IJIET, e-ISSN 2548-8430, p-ISSN 2548-8422, Vol. 1, No. 1, January 2017

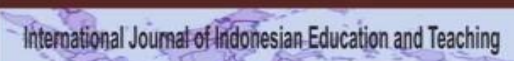

IJIET

International Journal of Indonesian Education and Teaching

http://e-journal.usd.ac.id/index.php/IJIET

Sanata Dharma University, Yogyakarta, Indonesia

\title{
TEACHING AND LEARNING SCIENCE: STUDENTS' PERSPECTIVE
}

\author{
Rohandi \\ Fakultas Keguruan dan Ilmu Pendidikan \\ Universitas Sanata Dharma, Yogyakarta \\ rohandi@usd.ac.id \\ https://doi.org/10.24071/ijiet.v1i1.329
}

\begin{abstract}
There is widespread concern for the situation of school science regarding contents and teaching methods. In this study, based on open questionnaire data, we explore Indonesian students' difficulties and their learning preference in science at two secondary schools students. In this paper how students perceive science as asubject and how the science instruction are expected to happened in classroom setting are described and discussed. Based on findings, the teaching of science needs to be emphasized more on the relevancies to students' experiences and on knowledge in context.
\end{abstract}

Keywords: learning difficulty, learning science, science instruction

\section{Introduction}

Improving science education by emphasizing scientific inquiry, the education and science communities are challenged to transform students' experiences into science classrooms. New approaches to science teaching feature inquiry as essential for student learning. These approaches assume that students need to find solutions to real problems by asking and refining questions; designing and conducting investigations; gathering and analyzing information and data; making interpretations, creating explanations, and drawing conclusions; and reporting findings. Throughout improving the practices of science teaching, students learning are expected to be more active and relevant that will improve their achievement. However, poor performance on national and international tests, high dropout rates, lack of preparedness, and other pressing educational problems are still evident as an existing problem in massive efforts to realign approaches to excellence and equity (Fraser-Abder et al., 2006).

It is quite often that in classrooms the student's voice is silent, except in giving rote answers to questions from their teacher. Teachers spend most of their time teaching knowledge-based science in a learning environment that ignores their students' experiences and provides few opportunities for conceptual development. Students do not fully engage mentally in classroom because teaching and learning do not fit into their range of experience and because their voices might often be unheard. Students are viewed as knowledge consumers. When students are viewed only as consumers, their voices are often reduced to responses to the questions of teachers who know the "right" answers in advance and what is expected of them, silencing student critical thinking and creativity 
(Furman \& Barton, 2006). Inquiry-based science teaching should put emphasis on student voices as a central place in the learning process. This occurs in learning when students pose questions, gather and analyze evidence and construct arguments based on it, and communicate their findings to others (Furman \& Barton, 2006). Furthermore, science learning need to be connected with existing student's life so that students feel that science is practical, familiar with the beliefs and practices of their lives.

Engaging students in learning via a need learning environment may ensure that student could develop their personal involvement in fulfilling their needs. However, researchers and reformers recognize that what is missing in reform strategies is the creation of a personalized environment that promoting students' engagement and caring student-teacher relationships (Rascoe \& Atwater, 2005). Moreover, students' interest in learning science has to come from their own "concerns, interests, and experiences". Otherwise students will feel that learning science is not a priority unless science learning is an extension of their community activity. It has also been discovered that currently, science learning in schools does not serve the needs of students so that students' lack of interest occur and science is often perceived as a difficult subject.

\section{Students' Difficulties in Learning Science}

The difficulties in learning science often referred to students' inabilities to understand science or ideas when they learn science. This students' difficulty in learning is a crucial problem in order to understand science concept. The influenced factors of learning problem could be student as a learner, science as body of knowledge, teacher and even institution (school) that deliver an unsuitable curriculum (Logan, 1981). In terms of the student as a learner, for example Logan (1981) described that students' learning difficulties include: lack of ability, low motivation, slow learner, unwillingness to study hard and bad or inappropriate study habits.

The way in which science is taught in school and science problems given by the teachers which are sometimes very vague (Ornek et al., 2008), even incompatible with students' experiences in their daily lives are the common factors of students' difficulties. Teaching science in this situation, a mismatch between teaching approaches used by the teacher and the student's preferred learning could occur in the classroom context (Kempa, 1991). Teachers may have poor expectation, inappropriate communications and even poor teaching strategy and lack of appreciation of the students' background and culture.

In terms of teachers' communication, Kempa (1991) identified that language use, for example in relation to technical terms or the complexity of sentence structure and syntax used by the teacher (compared with the student's language), is the common problem. Students and their teacher might think differently in terms of difficulties which students faced in understanding science. It seems students and their science teachers live in different worlds. In some situations the difficulties in learning science could arise from the ways in which students use words with very different meanings from those used in the scientific community. Kempa also indicates that learning difficulties in terms of students' language and 
communication are numerous. The students need to understand the meaning of words. They should transform their language to scientific ones or vice versa.

In terms of the science knowledge, for example Angell et al. (2004) found that students find science as a difficult subject which has a high workload. A high workload might refer to the demand that students have to contend with science at once with different representations such as experiments, formulas and calculations, graphs, and conceptual explanations. In terms of scientific language, the understanding of science concept could refer to understanding the connection of words with the real world and understanding the meaning of mathematical symbols which have specific meanings that depend on the context within which the symbols are used. Moreover, Lozano \& Cardenas (2002) observed that students' difficulty is related to the students' understanding of the representation of the physics formulas or symbols that represent physics concepts.

According to Logan (1981), students in many developing countries face difficulties in learning science due to the incompatibility of their frame work that is related to language. The student's entire conceptual framework built in his own language is far different from the scientific framework. Furthermore Kempa (1991) identified that the nature of the students' ideas/knowledge system is inadequate with such knowledge in relation to the acquired science concept.

One of the other reasons that may be responsible for students' failure to learn science is their lack of interest and attention. For example in terms of learning the concept of electricity, von-Rhöneck et al. (2007) identified that interest is seen to have a positive effect on physics performance. However, students need to allow themselves to be motivated and sustained in their interest and values within a social climate of the student-teacher and even student-student relationship where the students are having good learning results.

Thus, it is important for a greater variety of learners that teachers are encouraged to identify students' experiences and culture, develop a suitable science instruction and improve students' attitudes and interest towards science when the teachers are working to improve the teaching of science. The science lessons that focuses on students' understanding which consider the nature ofscience, students' difficulties and appreciate their experiences and culture might have a positive impact on students' interests, learning outcome and satisfaction.

\section{Method}

This study took place in two sub-urban Junior High Schools in Indonesia. We administered a free-response questionnaire to approximately 107 students in the beginning of the second semester. The students were asked to write their responses to each of the questions related to their difficulties (included their reasons) to learn science topics and their reason, and their preferences (included their reasons) to involve in learning activities in classroom. Observations of teaching processes were also conducted to gain insight of what actually happen in learning activities. Questionnaires were administered to 36 students of grade VIII St. George Secondary School and 71 students of grade VII St. Paul Secondary Schools (both school names are pseudonyms). The responses to open questions were coded and categorized. The emerging themes are discussed. Since each 
response on the open questions could consist of several statements and be coded into one or more categories.

\section{Findings}

\section{Students' Difficulties in Science}

Many students in this study had experienced that "Science (Physics) is difficult." Handling computation in solving problem is the most evident among the students many difficulties. This may indicate that students also have a minimum ability in mathematics understanding, the interaction between physics/science and mathematics and set up of a correspondence between a symbol and a property in physics equations. However, they believed that science is related to "the real world." The following excerpts provided evidence for this situation in this study:

I have to elaborate laws, equations, and long complicated calculations. (Student Questionnaire_4, line 458)

There are many equations and often consist of difficult equations (Student Questionnaire_4, line 430)

I am always wrong in calculating using equation, because I do not understand the equation (Student Questionnaire_4, line 605)

[the equations] are difficult. There are many calculations and I have to memorize the equations (Student Questionnaire_4, line 493)

This difficulty leads the students to feel that certain contents in physics are uninteresting. The following table provides evidence of characteristics of uninteresting contents as described by students.

Table 1: The characteristics of uninteresting science contents

\begin{tabular}{lccc}
\hline & $\begin{array}{c}\text { Total } \\
(\mathrm{N}=107)\end{array}$ & Male (N=55) & Female (N=52) \\
\hline Difficult to understand & $48(45 \%)$ & $20(36 \%)$ & $28(54 \%)$ \\
Too many equations and computations & $44(41 \%)$ & $27(49 \%)$ & $17(33 \%)$ \\
\hline
\end{tabular}

The data in Table 1 show that more students faced the problem of learning difficulty, especially those who are from the lower performance school (St. Paul). There were $44 \%$ out of 71 students who had difficulty in handling computation. This may indicate that the students also have a minimum ability in mathematics understanding, and the interaction between physics/science and mathematics. There was another difficulty in the aspect of interpretation, that is, the setting up of a correspondence between a symbol and a property. Student felt that "the symbol is difficult to understand and remember" (Student Questionnaire_4, line 
521). It was found that more girls (54\% out of 52 girls) than boys ( $36 \%$ out of 55 boys) felt science was difficult.

Many students in this study said that "Physics is difficult." Even though students expressed that they saw physics as a difficult subject; they believed that science is still strongly related to "the real world." Based on the students" responses, the characteristics of physics contents are interesting to them as they are relevant to their daily life, easy to understand and interesting. As shown in Table 2, most students (46\% out of 107) felt interested in science if teaching science makes them understand science in an easy way. A close investigation on students' responses regarding the characteristic of interesting science contents, it was obvious that based on their perspective, physics concepts that do not contain many equations is easy to understand. The students were uninterested in learning science that directly representing physics in the form of equations and computations (see data in Table $1)$.

Table 2: The characteristics of interesting science contents

\begin{tabular}{lccc}
\hline & Total $(\mathrm{N}=107)$ & $\begin{array}{c}\text { Male } \\
(\mathrm{N}=55)\end{array}$ & $\begin{array}{c}\text { Female } \\
(\mathrm{N}=52)\end{array}$ \\
\hline Easy to understand & $49(46 \%)$ & $22(40 \%)$ & $27(52 \%)$ \\
Relevant to daily life & $22(21 \%)$ & $13(24 \%)$ & $9(17 \%)$ \\
Interesting & $19(18 \%)$ & $13(24 \%)$ & $6(12 \%)$ \\
Others & $16(15 \%)$ & $4(7 \%)$ & $12(23 \%)$ \\
\hline
\end{tabular}

Students (21\% out of 107) felt that approaching the physics concept through the context of everyday life made the content of physics more understandable and interesting. The following excerpts provided evidence for this argument:

It is easy to understand, it is always done in everyday activity. Force influence our life so do our life influence force (Student Questionnaire_3, line 388-389)

It is easy to be understood and applied in everyday life (Student Questionnaire_3, line 381)

Content which relevant to things that I do and feel (Student Questionnaire_3, line 409)

If it (the topic) much relates to nature and environmental around us, it is easier to comprehend and understand (Student Questionnaire_3, line 682-683)

I often practices (the concept) directly in house and school (Student Questionnaire_3, line 360)

They were able to see how physics concepts are related to their interests outside school, such as playing a musical instrument. It enabled them to talk to scientifically-minded peers' out-of-school about the physics of music that were 
related to students' knowledge of music and so they attempted the experiments in greater depth.

...for example the topic of sound, because I often play some musical instruments, I like it more when explaining the concept of sound (Student Questionnaire_3, line 404-405)

Students, especially girls, seem to feel that "exotic" topics like astronomy are closer to their life-world than mechanics, electricity, etc. The following excerpts provided evidence for this opinion

The nature is so beautiful and amazing, the mystery with in which no ending. It also teaches us to thank for a goodness and respect, and takes care of all the things in this nature that has been amazingly created by God (Student Questionnaire_3, line 444449)

I like the topic of solar system because I like planet. The planets are interesting because they have orbit, form and color even there is an existing ring with the planet. I wish to know their orbit and where they are from (Student Questionnaire_3, line 670-675)

It is likely if we see the objects in the sky, they are very beautiful. It is likely that there is something hidden within. (Student Questionnaire_3, line 701-705)

It is very amazing and I wish to know many things (Student Questionnaire_3, line 491)

\section{Students' Difficulties in Learning Science}

From this study, it was discovered that the students' difficulties in understanding science concepts are based on two reasons. First, was the difficulty due to uninteresting activities, and the second was due to their perceptions of the difficulties of science concepts.

In terms of learning science, solving problem and too much teacher talks are students' uninteresting activities. Solving problem was difficult, could not understand the problem, and memorizing required equations were all uninteresting activities. Furthermore, long periods of teacher talk was difficult to understand and boring. Moreover, the learning environment did not directly lead them to actively engage in deep and meaningful learning and they felt foreign or unfamiliar with their teacher's language of science.

Most students expected that the teaching process should be in the form of science experiment or other hands-on activities. Their responses demonstrated more informed view of students' preferences to the learning environment. This shows a critical problem in which learning revolves around the absence of access to participation in a meaningful science related activity.

Students prefer active learning strategies rather than the traditional methodof teaching. Students viewed experiments in terms of feeling exciting, have the 
benefit of activities, and help them to understand more of the concepts being learned. Students viewed that an experiment is the process of observation and drawing conclusions. Throughout this process and followed by comparing conclusions with other references provided, they expected to construct the concepts being learned. The students felt that this could make them to become an autonomous learner. Students need to have learning environment such as doing science that leads them to be actively involved in cooperating with their friends.

\section{Students' Uninteresting Activities in Learning Science}

There are two kinds of activities in learning science which students felt not interesting to be included in their learning. The activities were solving problems and too much talking by their teacher (See Table 3). Forty six percent (46\% out of 107 students) of students from both schools felt that solving problems was not interesting to them. The students of St. George (31\% out of 36 students) were not satisfied with the learning processes that include solving problems. In comparison, more students at St. Paul (54\% out of 71 students) maintained that solving problems were not interesting activities. The boys ( $53 \%$ out of 55 boys) were less interested in solving problems than girls (38\% out of 52 girls)

The students of St. George (72\% out of 36 students) were not satisfied with the learning process that was dominated by their teacher. On the other hand, only a small number of students at St. Paul (15\% out of 71 students) felt that teacher talk was not interesting. The students in St. George, whose parents are middle-class, usually experience parenting styles that allow them to be more self-directed.The percentage of boys and girls who were not interested in solving problem is nearly similar. Table 3 provides the data.

Table 3: Students' uninteresting learning activities

\begin{tabular}{lccc}
\hline & Total $(\mathrm{N}=107)$ & Male $(\mathrm{N}=55)$ & $\begin{array}{c}\text { Female } \\
(\mathrm{N}=52)\end{array}$ \\
\hline Solving problem & $49(46 \%)$ & $29(53 \%)$ & $20(38 \%)$ \\
Teacher talk & $37(35 \%)$ & $21(38 \%)$ & $16(31 \%)$ \\
\hline
\end{tabular}

There are three main reasons why students find the activities in learning were not interesting; that is in terms of activities that do not require students to understand science, instead they only focus on memorizing facts and equations, and other boring activities (see Table 4). There were $67 \%$ out of 49 students who saw that solving problems was not interesting as they experienced difficulty solving problems. The students felt that attempting problem-solving activities in learning was not interesting due to the difficulties of the problems themselves. They could not understand the problems. Moreover, they also felt that they needed to memorize the equation. A total of $20 \%$ out of 49 students had experience that memorizing required equations was uninteresting. However, only $6 \%$ out of 49 students felt bored while solving problems.

In terms of uninteresting teacher's explanation or talk; most students had experiences that the teacher's talk was difficult to understand. A total of $32 \%$ out 
of 37 students had this experience. From the students' perspective, the teacher's talk was also boring. Table 4 provides the students' reasons to uninterestingactivities.

Table 4: Students' reasons on uninteresting learning activities

\begin{tabular}{lcc}
\hline & $\begin{array}{c}\text { Solving problem } \\
(\mathrm{N}=49)\end{array}$ & $\begin{array}{c}\text { Teacher talk } \\
(\mathrm{N}=37)\end{array}$ \\
\hline Difficult to understand & $33(67 \%)$ & $12(32 \%)$ \\
Memorizing & $10(20 \%)$ & $3(8 \%)$ \\
Boring & $3(6 \%)$ & $7(19 \%)$ \\
\hline
\end{tabular}

Even though sometimes the teacher's talk was clear enough for students to comprehend, however, the learning environment did not directly lead to the students actively engaging in deep and meaningful learning. The students' reflections of their previous learning experiences validate this situation, such as:

... he [teacher] explained clearly, and also sometimes, there were students who did not pay attention to him. He only talked for himself. (Student Interview_3, line 12-13)

... when we were learning with him, we were sometime sleepy. (Student Interview_3, line 14)

... if he delivered a lesson, it looks like a monologue, unable to socialize to students. (Student Interview_2, line 7-8)

In terms of language, the students' responses showed that they felt differences or unfamiliar with their teacher's language. The following excerpts provide evidence for this situation:

...if he talked, the level of his language was very high, it looks like not to talk for children ... but for adult. ...yes... when he taught... for example ... gives an equation ... then ... his explanation ... less likely........ difficult to understand. (Student Interview_2, line 13-17)

...he usually ..., if he explains ...yes ...likely his language is too high, but he let students - had a chat with friends (Student Interview_2, line 19-20)

I had questions but I was afraid of him (Student Interview_3, line 22)

I wish he repeated (his explanation), but I was afraid to talk to him (Student Interview_3, line 23) 


\section{Students' Learning Preferences}

Most students expected the teaching process to be in the form of science experiments or other hands-on activities. Their responses demonstrated a more informed view of students' preferences for the preferred learning environment. There were $89 \%$ out of 107 students who prefer to learn science through hands-on activities. In other words, this showed a critical problem in learning which revolves around the absence of access to participation in meaningful sciencerelated activity. From classroom observation data in the early stage of this research, the traditional method of teaching science (chalk and talk method) whichhas been identified as teacher-centred is still dominant. This learning situation initiated different and varied responses among students. The students' responses to the questions which learning activities were not interesting, is as shown in Table 5.

Table 5: Students' interesting learning activities

\begin{tabular}{lccc}
\hline & Total $(\mathrm{N}=107)$ & Male $(\mathrm{N}=55)$ & $\begin{array}{c}\text { Female } \\
(\mathrm{N}=52)\end{array}$ \\
\hline Doing Science & $95(89 \%)$ & $49(89 \%)$ & $46(88 \%)$ \\
Discussion and group work & $17(16 \%)$ & $9(16 \%)$ & $8(15 \%)$ \\
Teaching through story & $3(3 \%)$ & $2(4 \%)$ & $1(2 \%)$ \\
Solving problem & $3(3 \%)$ & $1(2 \%)$ & $2(4 \%)$ \\
\hline
\end{tabular}

Table 6: Students' reasons for interesting learning activities

\begin{tabular}{lcc}
\hline & $\begin{array}{c}\text { Doing Science } \\
(\mathrm{N}=95)\end{array}$ & $\begin{array}{c}\text { Discussion and group work } \\
(\mathrm{N}=17)\end{array}$ \\
\hline Cooperative & $11(12 \%)$ & $11(65 \%)$ \\
Interesting & $27(28 \%)$ & $6(35 \%)$ \\
Easy to understand & $15(16 \%)$ & $0(0 \%)$ \\
\hline
\end{tabular}

In terms of students' preferences in learning science, there were reasons that through the activities listed in Table 5, they would feel more interested, easy to understand the topics, and would make them collaborate. Table 6 provides the data of the students' opinions.

From the students' perspective, they prefer active learning strategies rather than the traditional method of teaching. Most responses (28\% out of 95 students) indicated that students viewed experiments in terms of exciting feelings and are beneficial activities:

... because we are enjoying -not merely confronted with blackboard but with equipments- ... thus we understand more through activity with the real things (equipments, procedures) (Student Questionnaire_1, line 333-334) 
It is not boring, exciting and we are able to cooperate more with friends (Student Questionnaire_1, line 434-435)

... by doing a simple group activity/experiment, students shall not be bored and saturated. It is because up until now... it is seldom to learn physics through group-work and by doing experiment (Student Questionnaire_1, line 719-721)

The experiment is exciting, the reason is we are usually lazy and sleepy to listen to teacher's explanation, but if we are doing experiment, our sleepiness becomes disappear because of our enthusiasm and curiosity (Student Questionnaire_1, line 742-744)

Some students (16\% out of 95 students) emphasized that experiments help them to better understand the concept being learned. The students' responses are:

[we] can clearly understand a phenomenon, can learn together in finding out the solutions of the problem, sharing ideas and questioning with other groups (Student Questionnaire_1, line544546)

Because we can know and understand - we can discover something (Student Questionnaire_1, line 326)

It also appeared that students saw the main aim of experimental work in school physics/science as "showing the theory in practice."

[using experiment]... I can understand the theory more clearly and easily, so that it is easy for learning (Student Questionnaire_1, line 405)

Students viewed an experiment as the process of observing and drawing conclusions. Throughout this process, they participated by comparing conclusions with other provided references and eventually they expected to construct the concept learned. The students felt that this could make them become autonomous learners. The following excerpt provides evidence of the students' understandings:

By doing the observation, finding conclusion, and finding a relevant concept in references by myself. The reason is that students can find relevant information by themselves and they do not depend on the teacher (Student Questionnaire_1, line 553555)

Based on the students' position and perceptions, there appear to be a need to have a learning environment that also lead them to be actively involved in 
cooperating with their friends. A total of $16 \%$ out of 95 students saw that doing experiments in science would lead them to cooperate with their friends while learning.

\section{Discussion}

Students' inability to understand science concepts or ideas when they learn science is referred as the difficulties in learning science. The relevant factors of this difficulty might be student as a learner, science as body of knowledge, teacherand even institution (school) that deliver an unsuitable curriculum.

The description of findings regarding students' difficulties in learning science reflected the students' real experiences in learning science in an ordinary science classroom. Many of the students in this study felt that "Physics is difficult". This difficulty leads to the situation where the students felt that certain components of the contents in physics were uninteresting and they faced problemsin handling computation. The students' difficulty with doing-solving problem wasdue to the difficulty in understanding the problem and also the requirement to understand the meaning of equations being used. Angell et al.(2004) found a similar finding that students find science difficult because they have to contend with different representations such as experiments, formulas and calculations, graphs, and conceptual explanations at the same time. Moreover, they have to make transformations among them. This finding shows that students struggle with physics not only due to the complexities of the subject, but also due to inadequacies with their skills and knowledge of mathematics. This reflects the complexity of the interaction between physics/science and mathematics, as a valuable input to assist in the design of appropriate learning activities and materials for the development of specific scientific concepts. Furthermore, Villani (1992) points out the fact that it is common for students of science to show a reluctance to use mathematical language, basically due to the difficulties they have concerning its interpretation. This might indicate that students also have minimum ability in understanding mathematics, and the interaction between physics/science and mathematics. There was another difficulty in the aspect of interpretation; that is, the setting up of a correspondence between a symbol and a property. Attention need to be given by the science teachers to the importance of providing special attention to the interpretation of the symbolism that appears in such mathematical models. A greater attention should also be paid to this neglected area, especially in the earlier physics learning.

The symbolic language used in the formalization of certain components into equations became difficulties for the students' understanding of the symbol and its property. Sherin (2001) argued that in the teaching and learning of physics, learning to build mathematical models of the physical world is a central goal of physics instruction. The structure of the models inherent in physical principles andequations should be made explicit for students. Furthermore, this view can be seenas part of a more general movement that takes models, not necessarily formulated as equations, as the targets of science instruction.

One of the factors of students' difficulties is teaching strategy delivered by teacher. The way in which the teacher implemented science lesson in classroom 
was not compatible with student. The findings in this study should be noted that students' difficulty in learning science might be parallel to their uninteresting learning activity. Two activities in learning science which the target students felt uninterested to be involved in are dominating teachers' talks and solving problems. The students just wrote what their teacher said without relating it to their experiences, and further applied it to their everyday lives. In this way, students did not understand science comprehensively. They only memorized facts and equations, and this was as boring activities. This finding supports the notion that teaching science in Indonesian schools has been reduced into a form of transmission of knowledge by delivering the content presented in school textbooks (Raka Joni, 2000, 2005; Semiawan, 2000). Similarly, Wahyudi and Treagust (2004) also found that most science teaching practices in rural lower secondary schools in Indonesia are teacher-centered and dominated by the traditional teaching method, namely, 'chalk-and-talk'. There were significant amount of evidence to suggest that this anomaly had occurred in Indonesian schools where the teaching and learning of science was concerned. Teaching which focused on students' activities was not considered. The teacher believedthat students could memorize rules and they could do it quickly. This might be particular to Indonesia, 'culturally bound', perhaps due to the inheritance of the derivative of oral culture where knowledge was transmitted in similar ways.

It was obvious that the science lesson observed in this study relied on memorizing as a primary learning strategy, which reinforced the view that knowledge is an absolute truth, and there is always an 'expected answer'. This is known by those who are the authorities (teachers). This system of learning does not encourage variation in thinking; in fact it does not even allow questioning or debate. For each question or issue there is seen to be only one acceptable answer. In class, this is the teacher's answer, the teacher's point of view. This is also similar to a finding that was found, for example, in China. Chan (1999) states that students from Confucian cultures are ingrained with respect for knowledge transmitted by authority figures, including teachers and textbooks, rather than the desire to seek and initiate inquiry and investigation. Students from cultures that respect authority may be receptive to teachers telling and directing them, rather than to inquire, explore, and seek alternative ways (Lee \& Fradd, 1998).

During the observation of the teacher's teaching, the lesson delivered by both teachers had left little time for students to acquire a deep understanding ofthe subject or to develop life-long skills such as critical thinking, problem solving, and communication. In general, the flow of the science classes went through a routine series of events that were constantly replicated. As a teacher entered the classroom, the students would automatically stand up as they responded to salutation and would wait for the silence indicating that, after taking the attendance, the class will continue on a linear path. In the case of going over anew topic, the teacher would introduce the topic by giving a short speech and writing the title on the blackboard. In case of difficulties, the teacher would be willing to help, which was something highly appreciated by the students. This situation fit well into what Tobin and McRobbie (1996) call "the cultural myths" in which teaching and learning science are heavily oriented towards the 
transmission of knowledge, being efficient, maintaining the rigor of the curriculum, and preparing students to excel in tests. Teaching is not telling students what the teacher knows but involving students in activities to experience how to learn. Learning is not memorizing a set of facts, but the ability to use resources to find, evaluate, and apply information.

As identified by Logan (1981), in developing countries students faced difficulties in learning science due to the incompatibility of their frame work that related to language. Findings of this study show a parallel situation. Many of the students had difficulties in understanding their teacher oral explanation. In terms of language, the students' responses showed that they felt foreign or unfamiliar with their teacher's language. Kempa (1991) indicates that particular aspects of 'language and communication' which cause learning difficulties are numerous, extending beyond the student's understanding of the meaning of words: the students must face tasks requiring the transformation from one type of language toanother. It is assumed that the word 'language' is used in a wide sense that includes all kinds of communication that can generate problems of interpretation during the teachinglearning process. For example as previously described, it can be pointed out that, certain specific problems concerning the use of mathematical language in Physics, especially problems that arise from the interpretation of its symbols. Throughout this finding, it seems that attention needs to be given by the teacher to the importance of providing the language scaffolding to facilitate the students' crossing the border into the language of science.

From this finding, the students seem to have learning difficulties related to the language used by the teacher and the scientific framework. The students described their teacher's language as "high-level language". The student's entire conceptual framework is built into his own language that might be far different from the scientific framework. In term of this learning difficulty, Kempa (1991) mentions various factors as responsible for the 'difficulties in the learning of physics/science', among which he mentions in the following:

Communication problems arising from language use, e.g., in relation to technical terms or to general terms with contextspecific specialized meanings, or the complexity of sentence structure and syntax used by the teacher (compared with the student's own language capacity) (p.120)

The students' difficulties in understanding their teacher's language might have further impact on their limited ability in understanding science by listening to the oral explanation. Oral physics/ science is closely related to language and literacy development (Lee, 1997). Students with limited literacy development in reading and writing often have not developed abstract and hypothetical reasoning. These students also experience difficulties understanding "appropriating" scientific modes of discourse. Thus, they face the challenge of learning to talk in physics/science as well as developing literacy simultaneously (Lee, 1997).

In actual classroom practices in both schools, the teacher's authority was observed as dominant, especially when the teacher is considered as being superior to all the students in the classroom. As this study was conducted in a Javanese 
society and since both teachers are Javanese, the hierarchical order based on a person's position or status is highly respected in the Javanese culture. The Javanese culture emphasizes obedience to elderly and/or authoritative figures (Magnis Suseno, 1993; Mulder, 1992, 1996) including teachers. According to the Javanese world view, social relationships should be well ordered and combined into a harmonious totality. Such relationships are hierarchically organized, with people having certain status positions that relate to each other in morally unequal ways (Magnis-Suseno, 1993; Mulder, 1992, 1996). Everyone should know his or her place and duty, honoring and respecting those in higher positions, while remaining compassionate toward and responsible for, those in lower positions (Mulder, 1978). On the other hand, Javanese culture is not conducive for the development of critical thinking ability (Chandra, 2004). A Javanese studentmight take too much time building the courage to put him- or herself to take onthe authoritative figures.

Even though students expressed that they saw physics as a difficult subject; they believed that science is still strongly related to the real world. Based on the students' responses, the characteristics of physics contents that were interesting to them were also relevant to their everyday life, easy to understand and interesting. For most students, to be interested in science, the teaching of science should make them understand science in an easy way, such as approaching everyday life in the form of science experiment or other hands-on activities. In this way, they were able to see how physics concepts related to their interests outside school as they experience everyday life activities.

Based on the beliefs and opinions of students in this study and findings from other research, it could be imagined that the value of supporting students in bringing their interests, experiences, ideas, and emotional responses to science, if they are to be producers of science (Fusco, 2001). Furthermore, Fusco (2001) indicated that, if students encountered any genuine problems they were likely to discharge their science experiences in school as boring or not related to their lives or futures. According to Fusco (2001), youths are disengaged from school science if their funds of knowledge were not incorporated into the science curriculum.

For students to develop their interest in science, their teacher needs to create space in which school science experience and students' funds of knowledge intersect. The students' funds of knowledge are acknowledged as integral and relevant to learning. In this way, the students will be comfortable drawing freely on their linguistic and socio-cultural repertoires to solve a variety of problems together (Basu \& Barton, 2007).

Thus, interest in science is seen as a relation among other things by the knowledge a student has in the field; his or her science related self-concept, experience of competence, and self-determined engagement. It also includes various emotional and affective components. The interest could also emerge from the student's interaction with his or her environment.

\section{Conclusion}

Evidences from this study show that the students dislike the way in which their teacher relied heavily on the content of science in teaching. The broad 
message seems to be that students dislike such activities as the repeated presentation of scientific topics and the dictating or copying of notes. Students expect the learning of science to be more relevant to their everyday life, to include more practical/hand-on activities, and to provide greater opportunity for discussion and participation. This finding validates the importance of incorporating students' cultures and experiences into teaching science that implement or ensure instructional congruence in the teaching of science in an Indonesian setting, which is expected to promote students' engagement in the learning of science and thus making science accessible to more students.

In making science more accessible to students, it is important for teachers implement various strategies and encourage student to take more responsibilities. In the study, however, a variety of teaching methods even all are valuable as instructional tools such as hands-on activities, discussion, experiments, and developing various teaching materials need further improvement. But to begin this job regarding better ways of incorporating students' cultures and experiences into teaching science, the teachers still need to improve and diversify their teaching strategies. They need to put a greater emphasis on delivering inquiry-based and science knowledge in context in their teaching. This effort is expected to allow students to be involved in activities both individually and cooperatively in groups. In order this to happen, teachers need clear instructions in order to facilitate student learning.

\section{References}

Angell, C., Guttersrud, Ø., Henriksen, E. K., \& Isnes, A. (2004). Physics: Frightful, But Fun Pupils' and Teachers' Views of Physics and Physics Teaching. Science Education, 88, 683- 706.

Basu, S. J., \& Barton, A. C. (2007). Developing a sustained interest in science among urban minority youth. Journal of Research in Science Teaching, 44, 466-489.

Chan, S. (1999). The Chinese learner - a question of style. Education \& Training, 41(6/7), 294-304.

Chandra, J. S. (2004). Notions of critical thinking in Javanese, Batak Toba and Minangkabau culture. In Setiadi, A. Supratiknya, W. J. Lonner \& Y. H. Poortinga (Eds.), Ongoing themes in psychology and culture (Online Ed.). Melbourne, FL: International Association for Cross-Cultural Psychology.

Fraser-Abder, P., Atwater, M., \& Lee, O. (2006). Research in urban science education: An essential journey. Journal of Research in Science Teaching, 43(7), 599-606.

Furman, M., \& Barton, A. C. (2006). Capturing urban student voices in the creation of a science mini-documentary. Journal of Research in Science Teaching, 43(7), 667-694.

Fusco, D. (2001). Creating Relevant Science through Urban Planning and Gardening. Journal of Research in Science Teaching, 38(8), 860-877.

Kempa, R. (1991). Students Learning Difficulties in Science. Causes and Possible Remedies. Enseñanza de las Ciencias, 9(2), 119-128. 
Lee, O. (1997). Diversity and Equity for Asian American Students in Science Education. Science Education, 81, 107-122.

Lee, O., \& Fradd, S. H. (1998). Science for all, including students from nonEnglish-language backgrounds. Educational Researcher, 27(4), 12-21.

Logan, P. (1981). Language and physics. Physics Education, 16, 74-77.

Lozano, S. R. D., \& Cardenas, M. (2002). Some Learning Problems Concerning the Use of Symbolic Language in Physics. Science \& Education, 11, 589- 599.

Magnis Suseno, F. (1993). Etika Jawa: Sebuah Analisa Falsafi tentang Kebijaksanaan Hidup Jawa. Jakarta: PT Gramedia Pustaka Utama.

Mulder, N. (1978). Mysticism and Everyday Life in Contemporary Java: Cultural Persistence and Change. Singapore: Singapore University Press.

Mulder, N. (1992). Individual and Society in Java: A Cultural Analysis. Yogyakarta: Gadjah MAda University Press.

Mulder, N. (1996). Inside Southeast Asia: Religion, Everyday life, Cultural change. Amsterdam: The Pepin Press.

Ornek, F., Robinson, W. R., \& Haugan, M. P. (2008). What makes physicsdifficult? International Journal of Environmental \& Science Education, 30(1), 30-34.

Raka Joni, T. (2000). Memicu perbaikan pendidikan melalui kurikulum dalam kerangka pikir desentralisasi, antara content transmision dan pembelajaran yang mendidik. In Sindhunata (Ed.), Membuka Masa Depan Anak-anak Kita (pp. 33-47). Yogyakarta: Kanisius.

Raka Joni, T. (2005). Pembelajaran yang Mendidik: Artikulasi Konseptual, Terapan Kontekstual dan Verifikasi Empirik. Jurnal Ilmu Pendidikan, 12(2), 91-127.

Rascoe, B., \& Atwater, M. M. (2005). Black males' self-perception of academic ability and gifted potential in advanced science classes. Journal of Research in Science Teaching, 42, 888-911.

Semiawan, C. (2000). Relevansi kurikulum pendidikan masa depan. In Sindhunata (Ed.), Membuka Masa Depan Anak-anak Kita (pp. 19-31). Yogyakarta: Kanisius.

Sherin, B. L. (2001). How Students Understand Physics Equations. Cognition And Instruction, 19(4), 479-541.

Tobin, K., \& McRobbie, C. J. (1996). Cultural myths as constraints to the enacted science curriculum. Science Education, 80, 223-241.

Villani, A. (1992). Conceptual Change in Science and Science Education. Science Education, 76(2), 223-237.

von-Rhöneck, C., Grob, K., Schnaitmann, G. W., \& Völker, B. (2007). Learning in basic electricity: how do motivation, cognitive and classroom climate factors influence achievement in physics? International Journal of Science Education, 20(5), 551-565.

Wahyudi, \& Treagust, D. F. (2004). An Investigation of Science Teaching Practices in Indonesian Rural Secondary Schools. Research in Science Education, 34, 455-474. 